\title{
Partial Rootzone Drying Irrigation Increase Root Surface Area, Root Hydraulic Conductivity and Water Use Efficiency in Maize
}

\author{
Wang Zhenchang ${ }^{1,2, ~}$, Yu Xiaofei ${ }^{1,2}$, Feng Liang ${ }^{1,2}$, Zhu Jianbin ${ }^{2}$ \\ ${ }^{1}$ Key Laboratory of Efficient Irrigation-Drainage and Agricultural Soil-Water Environment in Southern China, Ministry of Education, College \\ of Water Conservancy and Hydropower Engineering, Hohai University, Nanjing, China \\ ${ }^{2}$ College of Water Conservancy and Hydropower Engineering, Hohai University, Nanjing, China
}

Email address:

wangzhenchang@hhu.edu.cn (Wang Zhenchang), 165548159@qq.com (Wang Zhenchang)

${ }^{*}$ Corresponding author

To cite this article:

Wang Zhenchang, Yu Xiaofei, Feng Liang, Zhu Jianbin. Partial Rootzone Drying Irrigation Increase Root Surface Area, Root Hydraulic Conductivity and Water Use Efficiency in Maize. International Journal of Environmental Monitoring and Analysis.

Vol. 4, No. 6, 2016, pp. 146-153. doi: 10.11648/j.ijema.20160406.12

Received: November 21, 2016; Accepted: November 30, 2016; Published: December 5, 2016

\begin{abstract}
Partial root-zone drying (PRD) is an effective water-saving irrigation method and the heterogeneous soil moisture distribution induced by the method may affect root activities, crop water use efficiency and participation of different part of organ. The effects of deficit irrigation (DI) and PRD on leaf and root surface areas, root hydraulic conductivity $\left(\mathrm{K}_{\mathrm{R}}\right)$, and gas exchange and water use efficiency, were studied in maize (Zea mays L. cv., a local variety) grown in pots in the field for two months in the arid climate of Gansu Province, northwest of China in 2009. The PRD treatment was applied in two modes as PRD1 and PRD2, and they were obtained by the soil water content of the dry compartment had decreased to $18 \%$ (vol.) and $11 \%$ (vol.) (approximate $60 \%$ and 30\% of the pot holding capacity) before shifting side of irrigation, respectively. DI2 was irrigated with the same irrigation amount with PRD2, while water was equally separated to two compartments. The full irrigation (FI), PRD1, PRD2 and DI2 received 10.75, 8.70, 8.45 and 8.45 liters of water during the treatment period, respectively. The evapo-transpiration water use efficiency ( $\mathrm{WUE}_{\mathrm{ET}}$ ) was significantly higher in the PRD2 than in the DI2. PRD1 and PRD2 significantly $(P<0.05)$ increased the root surface areas compared to DI2 by $17.8 \%$ and $14.6 \%$, respectively, and that resulted in ratio of root surface area to leaf area of PRD2 significantly higher than that of DI2. Further, compared to DI2 and FI, PRD2 significantly $(P<0.05)$ increased $\mathrm{K}_{\mathrm{R}}$ by $15 \%$ and $34 \%$, respectively. The intrinsic WUE, the net photosynthesis $(\mathrm{A})$ and $\mathrm{g}_{\mathrm{s}}$ relationship $\left(\mathrm{A} / \mathrm{g}_{\mathrm{s}}\right)$, were the highest in the PRD2 treatment as compared with the other treatments on $4 \mathrm{f} 5$ occasions. On 3 out of 5 occasions, the $\mathrm{A} / \mathrm{g}_{\mathrm{s}}$ values of PRD2 plants were significantly higher than those of FI plants. Our results indicate that PRD2 increased root-shoot surface ratio and the root hydraulic conductivity and those might play a major role in enhancing $\mathrm{WUE}_{\mathrm{ET}}$.
\end{abstract}

Keywords: Maize, Partial Root-Zone Drying Irrigation, Root Surface Area, Root Hydraulic Conductivity

\section{Introduction}

Water shortage problems in the arid and semi-arid regions of China severely affect the sustainability of the agricultural systems. Various irrigation methods such as limited irrigation, non-full irrigation, deficit irrigation, partial rootzone irrigation have been recommended in this region in order to maximize crop water productivity [1].

Deficit irrigation (DI) is a method that irrigates the entire root zone with an amount of water less than the potential evapo-transpiration, and the mild stress has minimal effects on the yield [2] [37] [38]. Partial root-zone Drying (PRD) is a further development of DI; it involves irrigating only part of the root zone leaving the other part to dry to a predetermined level before the next irrigation. In such a way, PRD allows the induction of the ABA-based root-to-shoot chemical signaling to regulate growth and water use and thereby increase water use efficiency (WUE) [3] [7] [9] [10] [11] [14] [28] [43] [44] 
[45]. Accumulated evidence has demonstrated that, given a similar irrigation volume, PRD is superior to DI in terms of improvement in crop WUE, product quality and $\mathrm{N}$ use efficiency [8] [31] [33]. However, until now the mechanisms underlying these advantages of PRD in relation to DI remain largely elusive. Some researchers suggested that a fine-tuned stomatal control over transpiration induced by a stronger root ABA signal under PRD may partly account for the observed advantages under PRD treatment [30]. In addition, earlier studies have also indicated that keeping a high water content of the wet side in the PRD is essential to maintain a high leaf water potential of the plants [12] [13] [14]. However, it is thought that if soil water content of the dry part of the root system, during PRD irrigation, is becoming too dry, the fraction of sap flow from drying root declined, signal transmission will be limited as higher fraction of sap flow from the well irrigated part diluted the $[\mathrm{ABA}]_{\mathrm{xylem}}[17][18]$ [32]. Thus, rewetting the drying part of the root system at an appropriate soil water status may be crucial in maintaining the root-to-shoot ABA signaling system [3][18][32]. In addition, the drying and wetting cycles in the soil imposed by the PRD treatment also influence soil bio-physicochemical processes and thus the soil nutrients availability, Wang et al. [33] found that PRD significantly enhanced mineralization of soil organic $\mathrm{N}$ compared to DI with the same irrigation amount. Therefore, it is necessary to know how often the irrigation should be switched between sides in order to optimize the irrigation technique hereby maximizing crop WUE [32] [30].

Many physiological and morphological changes in the shoots of different crops under PRD have been reported [4] [5] [6] [10] [14] [33], whilst only a few studies have shown the effects of PRD on root growth and development [21] [25] [27] [34]. Tanasescu and Paltineanu [26] showed that irrigation affected the number of fine roots $(<1 \mathrm{~mm})$ which, in turn, influences the yield. Mingo et al.) [34] showed for tomato that root biomass might increase up to 55\% under partial root drying as compared to a uniform control receiving the same total amount of water. Similarly, experiments for the pot-grown maize under different irrigation regimes also indicated that PRD treatments could increase the root-to-shoot ratio and increase root biomass [5] [15] [35]. However, Wang et al. [27] indicated that there were hardly any significant differences in terms of morphology and yield as a result of the partial root-zone dying treatments, for which the total supply of water was the same as DI. The objectives of the present study were to assess how root growth and physiology were influenced by different irrigation regimes and thereby contribute to the improvement of WUE.

\section{Materials and Methods}

\subsection{Experimental Material and Growth Conditions}

The experiment was conducted in the field in shiyanghe Experimental Station for water-saving in Agriculture and Ecology of China Agricultural University from May to August in 2009 . The pots could be covered by plastic film when there was rain. Weather parameters (i.e. Light, relative humidity, temperatures and wind velocity) were monitored by an automatic-weather station less than 100 meters from the experimental site. Changes of weather parameter during the treatment period in 2009 were shown in Fig. 2. Maize plants (Zea mays L. cv., a local variety) were grown in pots $(25 \mathrm{~cm}$ in diameter at the top edge, $20 \mathrm{~cm}$ in diameter and $30 \mathrm{~cm}$ in depth) filled with loam soil. The soil had a volumetric soil water content (\%, vol.) of 29.0 at water holding capacity. The soil bulk density was $1.27 \mathrm{~g} \mathrm{~cm}^{-3}$, soil $\mathrm{pH}$ was 7.87 and organic matter content was $6.08 \mathrm{~g} \mathrm{~kg}-1$. The soil had a total $\mathrm{N}$ content at $0.89 \mathrm{~g} \mathrm{~kg}^{-1}$, total $\mathrm{P}$ content at $0.72 \mathrm{~g} \mathrm{~kg}^{-1}$, total $\mathrm{K}$ content at $13.80 \mathrm{~g} \mathrm{~kg}^{-1}$, available $\mathrm{N}$ at $55.93 \mu \mathrm{g} \mathrm{g}^{-1}$, available $\mathrm{P}$ at $8.18 \mu \mathrm{g}$ $\mathrm{g}^{-1}$ and available $\mathrm{K}$ of $163.0 \mathrm{mg} \mathrm{kg}^{-1}$ soil. Fertilizers were applied with $0.20 \mathrm{~g} \mathrm{~N} \mathrm{kg-1} \mathrm{dry} \mathrm{soil,} 0.1 \mathrm{~g} \mathrm{P}_{2} \mathrm{O}_{5} \mathrm{~kg}^{-1}$ dry soil and $0.07 \mathrm{~g} \mathrm{~K}_{2} \mathrm{Okg}^{-1}$ dry soil in the form of $\mathrm{N}$ was supplied as urea. $\mathrm{P}$ and $\mathrm{K}$ were applied in $\mathrm{KH}_{2} \mathrm{PO}_{4}$ form. All fertilizers were applied with analytical reagents and mixed into the soil in powdered form at the commencement of the experiment. Each pot was evenly separated with plastic sheets into two sub-parts of equal volume, between which no water exchange occurred. Each sub-part was filled with $8 \mathrm{~kg}$ air-dry soil and 3 $\mathrm{cm}$ thick sand layer at the bottom of the pot. In order to reduce soil evaporation and prevent soil surface hardening, a perforated PVC tube ( $2 \mathrm{~cm}$ diameter) was vertically installed in each sub-part down to a depth of $15.4 \mathrm{~cm}$ and used for irrigation. Each PVC tube was wrapped with two layers of window mesh to help water dispersal. All pots were irrigated up to $100 \%$ water holding capacity before planting. The seeds were sown in germinating boxes in the greenhouse at the beginning of April, 2009 and then transplanted to pots with roots fairly evenly distributed into the two separated sub-parts 20 days later. Actual soil water content in both soil compartments was measured by WET (Delta-T, UK) and the soil volume concerned. The water used for the irrigation was tap water with negligible concentrations of nutrients.

\subsection{Irrigation Treatments}

Four weeks after transplanting, the plants were subjected to four irrigation treatments: (1) full irrigation (FI) in which both soil compartments were watered daily at $18: 00 \mathrm{~h}$ to $29 \%$ to compensate fully for the water loss during the previous day; (2) partial root-zone drying (PRD1) in which one soil column was irrigated daily to about $29.0 \%$ (Vol.\%) ( while the other was allowed to dry until the soil water content of the dry compartment had decreased to $18 \%$ ( approximate $60 \%$ of the pot holding capacity), then the irrigation was shifted; (3) PRD2, in which one soil column was irrigated daily to $29.0 \%$ while the other was allowed to dry until the the dry soil had decreased to about $11 \%$ (approximate $30 \%$ of the pot holding capacity), then the irrigation was shifted; (4) DI2, in which a same irrigation volume of PRD2 was evenly irrigated to the two soil compartments.

\subsection{Measurements}

Daily water uptake from each soil columns of the FI, PRD1 
and PRD2 and DI2 plants was calculated based on the WET (Delta-T, UK) measurements. The soil water content was observed twice per day (at 09:00 and 20:00) during the experiment period. The mean soil water potential $\left(\psi_{\mathrm{s}}\right)$ of each compartment was then obtained based on the water retention curve (Fig. 1). Net photosynthesis (A) and stomatal conductance rate $\left(\mathrm{g}_{\mathrm{s}}\right)$ were measured at about 10 o'clock in sunny days. Gas exchange measurements were made at $380 \mathrm{ppm}$ of $\mathrm{CO}_{2}$ concentration by using a portable infrared gas analyzer Li-6400 (Li-COR Biosciences, UK Ltd.). Plant leaf area was measured with a leaf area meter (AM-300, UK). Plants were harvested at the fully mature stage. The above ground plant material was clipped at the soil surface and removed before roots were sampled

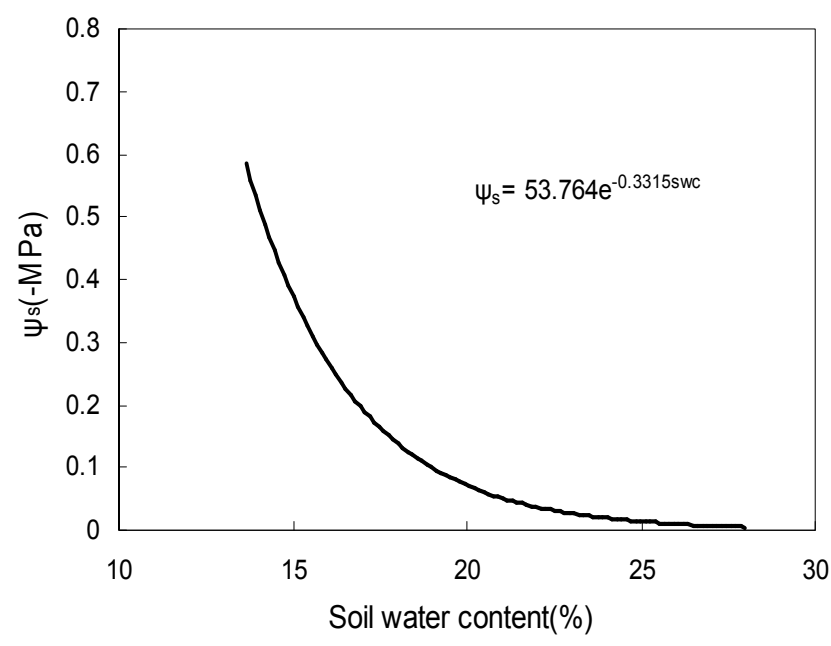

Figure 1. Water retention curve of soil used in the pot grown maize experiment in 2009.

The whole root system hydraulic conductance $\left(\mathrm{K}_{\mathrm{R}}\right)$ was measured in four plants per treatment in the laboratory. Maize plants were watered to preset treatments the night before the measurements. $K_{R}$ measurements were carried out early in the morning. The root systems were kept in their substrate and perfused with distilled and de-gassed ultra-pure water filtered through a $0.1 \mathrm{~m}$ water filtration membrane using the high pressure flow meter method (HPFM, Dynamax, USA) connected to the stump. KR was measured in a transient way within a range of $0-0.5 \mathrm{MPa}$ pressures at a constant rate of 3$5 \mathrm{kpa}-1$ and the flow rate (F)was recorded every $3 \mathrm{~s}$ as described by Tyree et al. (1995) [22]. F was plotted versus pressure $(P)$, and $K_{R}$ was estimated as the slope of a linear regression between both variables $(\Delta \mathrm{F}, \Delta \mathrm{P}) . \mathrm{K}_{\mathrm{R}}$ was corrected for air temperature. Laboratory air temperature was registered in each measurement and varied no more than $2^{\circ} \mathrm{C}$ during any set of measurements. Soil temperature was assumed to be the same as air temperature. The root in different soil compartments were washed manually (Böhm 1979) [23], and the cleaned roots were scanned on a professional root scanner (WinRHIZO, REGENT, Canada) with transparency adapter digital image analyses. Root surface area and root length could be measured at the same time. After that, the roots were oven-dried at $80^{\circ} \mathrm{C}$ for $72 \mathrm{~h}$ and dry weights were recorded.
The shoot samples were also oven-dried at $80^{\circ} \mathrm{C}$ for $72 \mathrm{~h}$ and dry weights were recorded.

\subsection{Water Use Efficiency (WUE) Calculation}

Intrinsic water use efficiency of leaf $\left(\mathrm{WUE}_{\mathrm{In}}\right)$ was estimated as the ratio between $A$ and $g_{s}\left(A / g_{s}\right)$. Evapotranspiration $(E T)$ under varying watering regimes was calculated using the soil water balance equation for the growing seasons as follows:

$$
\mathrm{EI}=\mathrm{I}+(\mathrm{Mi}-\mathrm{Mf})
$$

Where I is the irrigation application, Mi is the starting soil moisture before transplanting, $\mathrm{Mf}$ is the soil moisture at final harvest. Water use efficiency (WUEET) for each treatment was calculated as total above ground biomass (BIO) divided by seasonal evapotranspiration $(E T)$ :

$$
W U E_{E T}=B I O / E T
$$

\subsection{Statistical Analysis}

Data were analyzed by one-way analysis of variance (ANOVA). When it was necessary the data were transformed to assure ANOVA assumptions. All statistical analyses were performed using the SPSS 13.0 statistical package (SPSS Inc., Chicago, USA).

\section{Results}

\subsection{Soil Water Content and Soil Water Potential Dynamics}

Changes of soil water content and $\psi_{\mathrm{s}}$ in the FI- PRD- and DItreatment are shown in Fig. 3a and Fig. 3b. $\psi_{\mathrm{s}}$ of the drying side of the PRD plants and both sides of the DI plants decreased slowly during the first 14 days and decreased quickly thereafter until re-irrigation, reflecting the increasing size of the plants. FI plants were always irrigated near $\psi_{\mathrm{s}}$ of $-0.01 \mathrm{MPa}$; before each shift of irrigation, $\psi_{\mathrm{s}}$ of the PRD1 drying side decreased to about $-0.2 \mathrm{MPa}$, and $\psi_{\mathrm{s}}$ for PRD2 reached to approximately -0.7 $\mathrm{MPa}$, except on day of 13 th July where it decreased to about $-0.9 \mathrm{MPa}$ during the period of high amount water use. Number of times of shifting irrigation from one side to the other side occurred 6 times for PRD1 treatment and 3 times for PRD2. From Fig. 3, we could also see that alternating irrigation in the treatment of PRD (PRD1, PRD2) mostly happened in the last 20d, this was due to the following reasons: firstly, plants growth rate were much faster from 14th June to 3rd July than from 15th May to 13th June (Data not shown). Secondly, the relatively higher VPD and higher temperature, especially in the 10 days during the treatment, also contributed to the higher water consumption. In drying soils, very small changes in water content could lead to very large changes in water potential. As could be seen from Fig. 3, the difference of soil water content in the drying compartment for the 9th of July and 13th of July was no more than $1 \%$, but the difference between their $\psi_{\mathrm{s}}$ was more than $0.2 \mathrm{MPa}$. This big difference between their soil water potential could affect the PRD response of plants [31], so keeping the accuracy of the water content sensor, especially for 
the drying part, may be important.

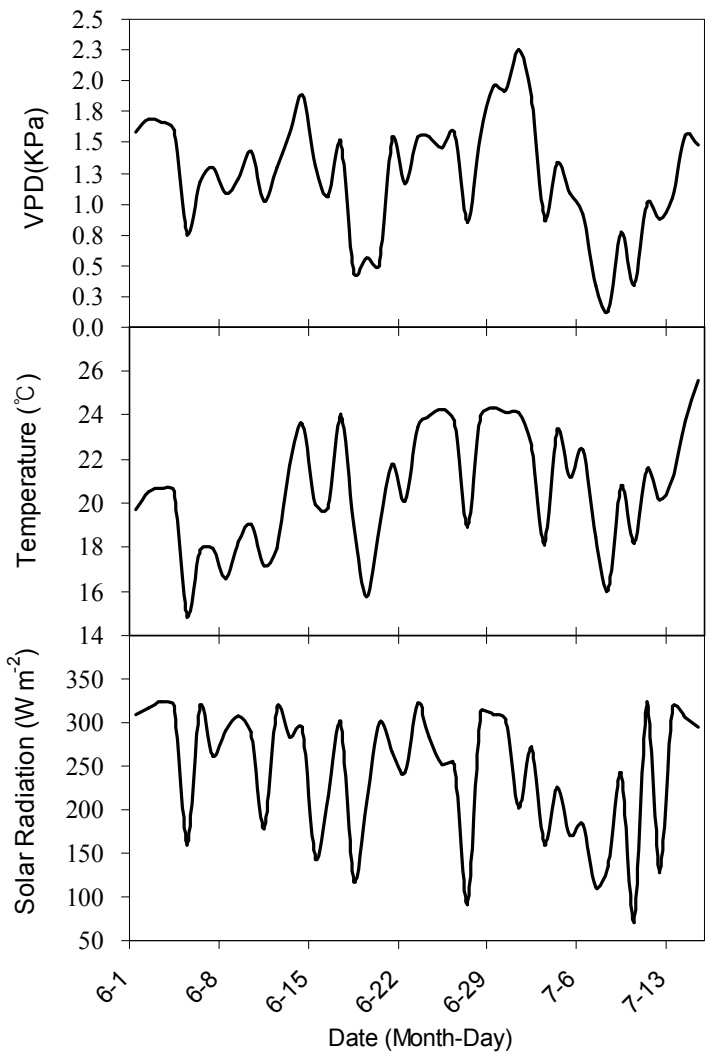

Figure 2. Changes of weather parameter (VPD, Air Temperature, Solar Radiation) during the treatment period in 2009.

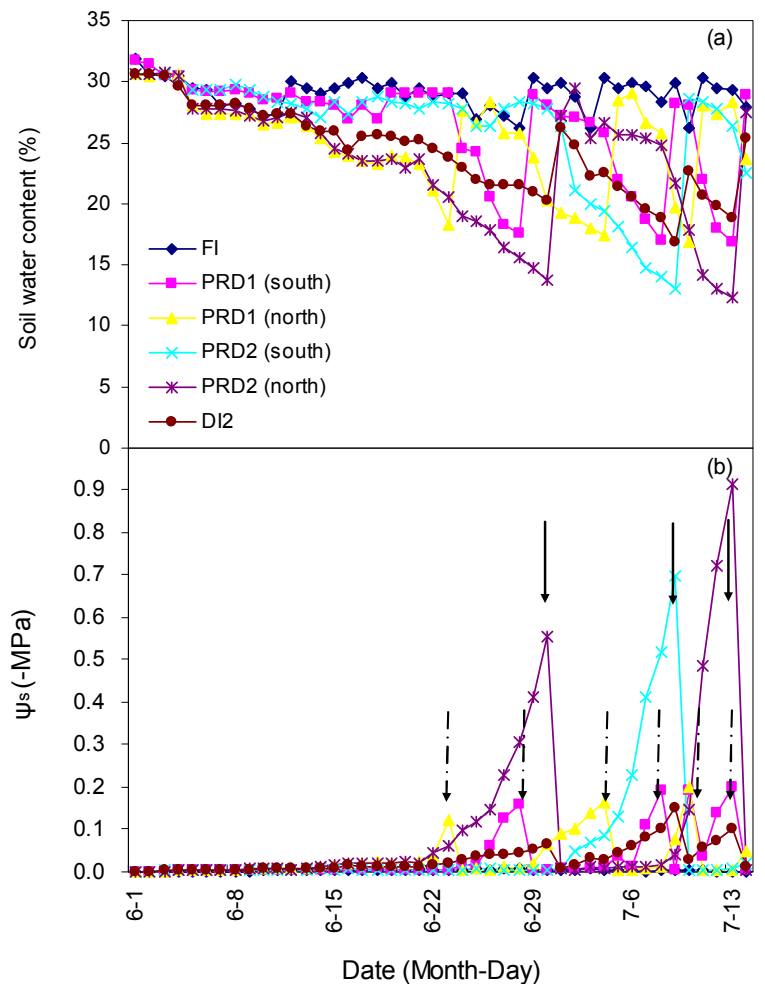

Figure 3. (a) Changes of soil water content for all treatments in the pot grown maize; (b) Changes of $\psi_{s}$ for all treatments in the pot grown maize (The solid and dashed arrows indicate the time of shifting irrigation for PRD1 and $P R D 2$, respectively).

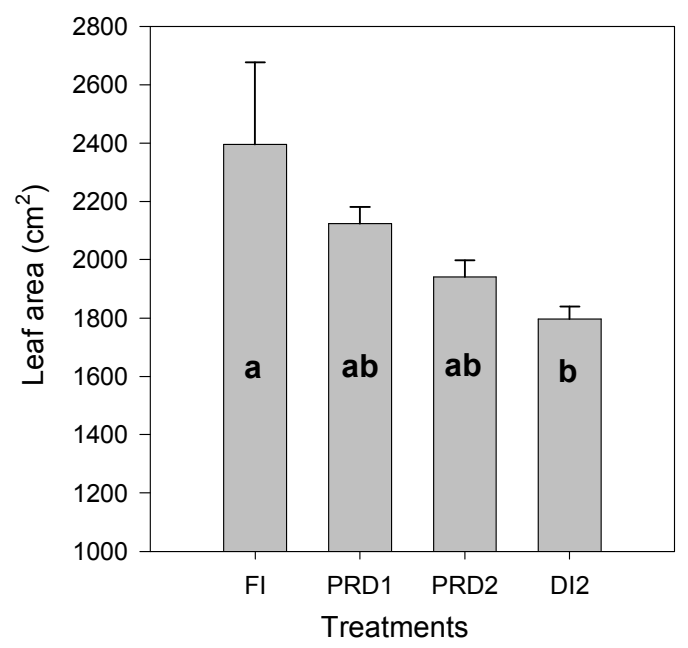

Figure 4. Leaf area under different irrigation treatments of maize in July 2009. The different letters indicate significant differences, Bars indicate $\pm S$. E $(n=4)$.

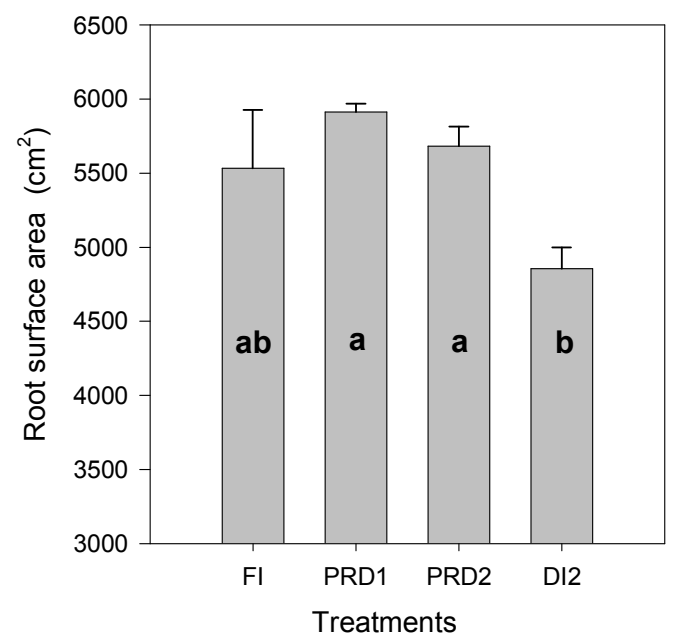

Figure 5. Root surface area of different irrigation treatments of maize in July 2009. The different letters indicate significant differences, Bars indicate $\pm S$. E. $(n=4)$.

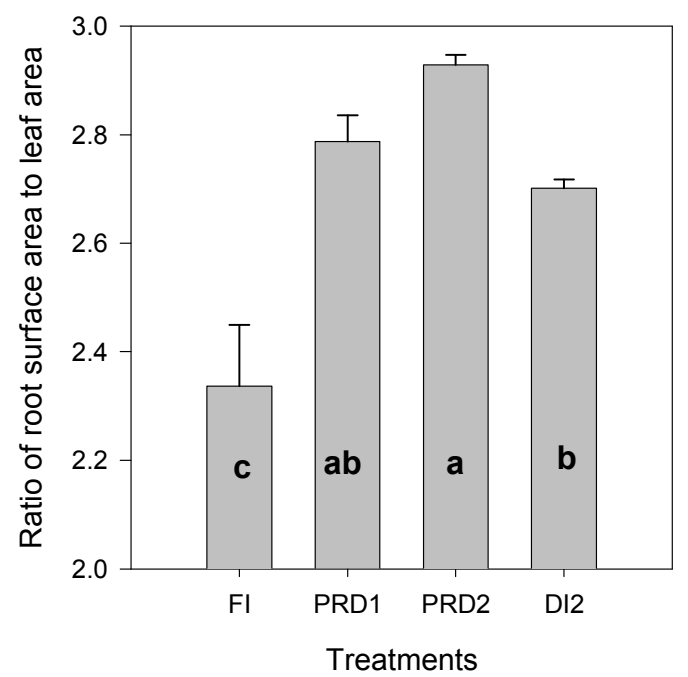

Figure 6. Root surface area of different irrigation treatments of maize in July 2009. The different letters indicate significant differences, Bars indicate $\pm S$. E. $(n=4)$. 


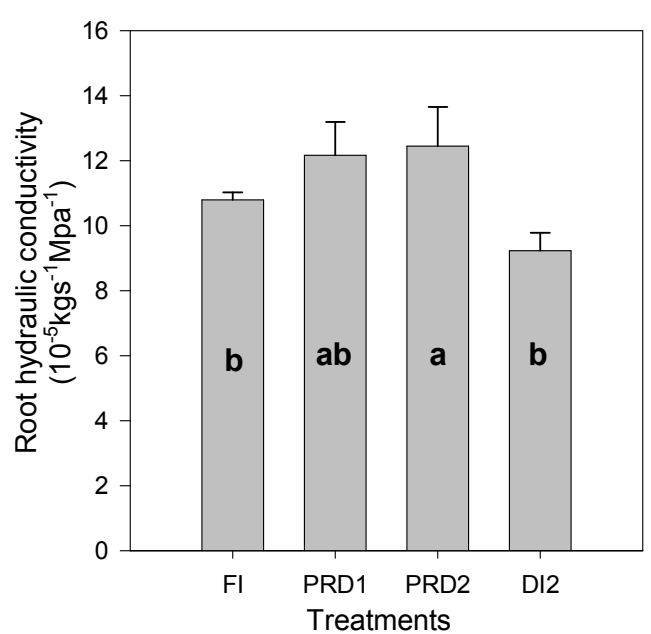

Figure 7. Root hydraulic conductivity under different irrigation treatments of maize in July 2009. The different letters indicate significant differences, Bars indicate $\pm S$. E. $(n=4)$.

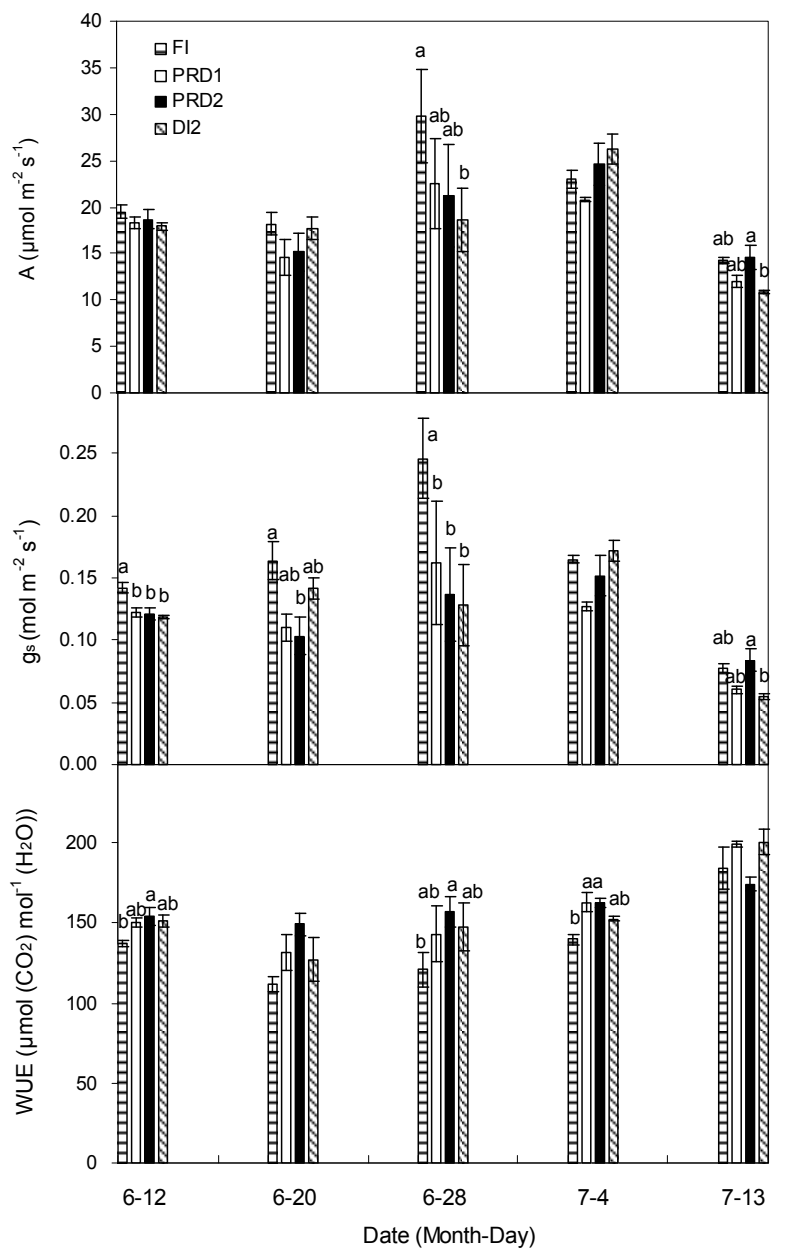

Figure 8. Net Photosynthesis rate (A), stomatal Conductance (gs) and intrinsic WUE in all treatments (FI, PRD1, PRD2, DI) of seeding maize in different growing stages. Data represent means and error bars are $\pm S$. E. For each day, bars with different letters are significantly different at $P<0.05$ $(n=4-5)$.

\subsection{Leaf and Shoot Area and Root Hydraulic Conductivity}

Compared with plants under PRD1, PRD2 and DI2, the plants of FI had the largest total leaf area, and it was almost $33 \%$ and $23 \%$ larger than that of DI and PRD2, respectively. However, there was only significant difference between FI and DI (Fig. 4). Fig. 5 shows that the PRD1 treatment had the largest root surface areas, followed by PRD2 and FI; the DI2 treatment had the smallest root surface area at the end of the experiment. The ratios of root surface area to leaf area of different irrigation treatment were shown in Fig. 6 at the end of the experiment. The ratio of FI was significantly lower than the ratio of the other treatments. PRD2 had the highest ratio, higher than the ratio of the PRD1 and significantly higher than that of the DI2 treatment ( $8 \%)$. The maize plants grown under PRD2 had significantly $(P<0.05) 34 \%$ higher KR values (the PRD2 being significant higher) than DI2 treatments (Fig. 7).

\subsection{Gas Exchange}

Net photosynthesis (A) of FI plants were higher than that of DI plants on four out of five occasions, and on two of those occasions it was significantly higher than that of DI plants; although A of FI plants was higher than that of PRD2 plants on four out of 5 occasions, there was no occasion where A of FI plants was significantly higher than of PRD2 treated plants (Fig. 8). During the treatment period, A of PRD1 plants were similar to A of the PRD2 plants. Stomatal conductance $\left(\mathrm{g}_{\mathrm{s}}\right)$ of PRD2 was significantly lower than that of FI on 2 out of 5 occasions. The gs values of the DI2 and PRD2 tended to be lower than those of the FI treatment. The intrinsic WUE $\left(\mathrm{A} / \mathrm{g}_{\mathrm{s}}\right)$ was significantly higher in PRD2 as compared with other treatments on 4 out of 5 occasions, and on 3 out of 5 occasions the $\mathrm{A} / \mathrm{g}_{\mathrm{s}}$ values of PRD2 plants were significantly higher than of FI plants, while as for DI plants, this was the case only on one out of five occasions.

\subsection{Above-Ground Biomass Production and WUE $E_{E T}$}

Total biomass was recorded at the end of the experiment, and no significant differences were found between FI, PRD2 and PRD1 treatments, but there was significant difference between FI and DI (Tab.1). WUE $\mathrm{ET}_{\mathrm{ET}}$ was the lowest for FI, and significantly $13 \%$ lower than that for PRD2.

Table 1. Above ground biomass and WUE $E_{E T}$ of spring maize under different irrigation treatments during 2009.

\begin{tabular}{llll}
\hline Treatments & Irrigation amount $(\mathrm{L})$ & Dry mass $(\mathrm{g})$ & WUE $\left(\mathrm{kgm}^{-3}\right)$ \\
\hline FI & 10.75 & $86.9 \mathrm{~A}^{\mathrm{a}}$ & $8.02 \mathrm{C}$ \\
PRD1 & 8.70 & $78.3 \mathrm{AB}$ & $8.14 \mathrm{~B}$ \\
PRD2 & 8.45 & $80.1 \mathrm{AB}$ & $8.37 \mathrm{~A}$ \\
DI2 & 8.45 & $72.6 \mathrm{~B}$ & $8.1 \mathrm{~B}$ \\
\hline
\end{tabular}

a. Mean values within the same column followed by different letters are significantly different at $\mathrm{P}_{0.05}$ level. Data represent means $(n=6-8)$

\section{Discussion}

Partial root-zone drying (PRD) has been proven an effective water-saving irrigation method [10] [16]. In this study, PRD2 reduced shoot abiomass slightly, but saved water consumption, 
and thus increased $\mathrm{WUE}_{\mathrm{ET}}$ significantly (approximate 13\%) compared to FI. Our results were in agreement with some previous reports [10] [15] [29]. It is generally believed that significant improvement of crop WUEET under PRD can be attributed mainly to a lowered stomatal conductance, a restricted leaf expansion and increased root growth regulated by the root-to-shoot ABA signaling induced by partial soil drying [14]. However until now the effects of PRD and DI on root morphology has only been studied to a limited extent and the effects on $K_{R}$ has not been reported as far as we know.

Keeping high soil water content in the wet side and preventing the dry side becoming too dry are essential to optimize signal transmission effect of PRD treatments [12] [13] [14] [18], also alternation of wet and dry compartments of PRD-grown plants may have more physiological consequences in terms of root water and nutrient uptake, our results indicated that PRD2 significantly increased root surface area compared to DI2 (Fig. 5).

In this experiment, total leaf surface area of the FI plants was significantly higher than the DI and the PRD2 treatments (Fig.4). Even though there was no significant difference for the root dry weight of PRD2 and DI (data not shown), the root area of the PRD2 plants were significantly larger than of the DI plants (Fig. 5). This might be a result of bigger specific root weight $\left(\mathrm{m}^{2}\right.$ root area/g root dry weight) (data not shown). The promotion of root surface in PRD might be associated with the alternation of wet and dry compartments resulting in a flush of new secondary roots [29] [36]. As for the physiological response of root under different irrigation regimes, we could find that maize grown under PRD2 showed significant $(P<0.05)$ higher value of $\mathrm{K}_{\mathrm{R}}$ than those grown under FI and DI (Fig. 7). Recently literatures suggested that ABA concentration in xylem ([ABA $\left.]_{\text {xylem }}\right)$ content could significantly enhanced in PRD compared to DI with the same irrigation amount [31] [33]. Increasing ABA concentration could contribute to increase root hydraulic conductivity by stimulating the activity of aquaporins [19] [39] [40] [41], as well as promoting root growth under drought stress [20]. Significant higher ABA concentration as well as larger root surface areas in the treatment of PRD2 than that of DI2 might induce the significant higher root hydraulic conductivity in PRD2. The reaction of promoting the growth of root system (Fig. 4) together with the restricting leaf area expansion (Fig. 5) resulted in significant higher ratio of root surface area to leaf surface area for the treatment of PRD than DI and FI (Fig. 6). This is in agreement with findings in several studies of pot-grown maize [4] [5] [15] and other species [34] [24], even though they reported on the ratio of root dry biomass and leaf dry biomass, not the root surface area and leaf area. It is clear that both these effects of ABA on roots may lead to an increase of water uptake and thus postpone the development of water deficit in the shoot [14]. Other results indicated that there were hardly any significant differences in terms of morphology and yield as a result of the partial root-zone dying treatments, for which the total supply of water was the same as DI [27]. The reasons for the discrepancy among those results are not clear.

As for the physiological response of leaf, it is obvious that in the experiment A was less sensitive to PRD treatment than gs. As a consequence of this, intrinsic WUE $\left(A / g_{s}\right)$ was increased under PRD2 (Fig. 8), this was in agree with the founding by previous researchers [1] [5] [25]. It was both the monopoly and physiological response of root and shoot under PRD, a heightened capacity for the collection of water and nutrient and maintaining the shoot in a well-hydrated condition, that result in a significant higher $\mathrm{WUE}_{\mathrm{ET}}$ compared to DI (Table 1). Based on these results, it is believed that PRD2 with shifting irrigation from one side to another when the soil water potential of drying side reached to about $-0.6 \mathrm{MPa}$, may have resulted in better physiological response than DI and PRD1, which shifting irrigation when the soil water potential of drying side reached to about -0.2 MPa. It was reported that stomatal closer in some species was relatively insensitive to soil drying, stomatal conductance of some kind plants in drying soil were not affected until an estimated soil water potential of around $-0.3 \mathrm{Mpa}$ had developed [42]. The relatively higher soil water potential in the drying compartment of PRD1 (>-0.2Mpa) might diminish the stomatal responses of PRD1 treatment compared with PRD2. Interestingly, from Fig. 8 we could see that $g_{s}$ of DI in the date of 13 th July was significant $(P<0.05)$ lower than that of PRD2, consequently WUE was the highest in all the treatments, which was contrast to the values of other four days. With the consideration of the soil water potential changes in that day (Fig. 2), it might be explained as follows: when soil water content of the dry part of the root system becoming too dry $(<-0.9 \mathrm{Mpa})$, the fraction of sap flow from drying root declined, signal transmission will be limited as higher fraction of sap flow from the well irrigated part diluted the $[\mathrm{ABA}]_{x y l e m}[31]$, and thus resulted in significant lower WUE compared to DI. Therefore, keeping the drying part of PRD treatment in suitable soil water potential conditions (not too high and not too low) may be important to the good effects of PRD.

\section{Conclusion}

Partial root-zone drying irrigation (PRD) could significantly increase the root surface areas, root-shoot surface ratio and root hydraulic conductivity compared to deficit irrigation (DI) which was irrigated with the same irrigation amount with $\mathrm{PRD}$, and that may play a major role in enhancing $\mathrm{WUE}_{\mathrm{ET}}$ in maize. In addition, keeping the drying part of PRD treatment in suitable soil water potential conditions might also influence the effects of PRD.

\section{Acknowledgment}

We are grateful for Grants from National Key Research and Development Program of China during the 13th Five-Year Plan Period (2016YFC0400208), The National Natural ScienceFoundation of China [51309080], The Fundamen-tal Research Funds for the Central Universities (2013B06014), and Water Conservancy Science and Technology Project of Jiangsu Province. 


\section{References}

[1] Kang S, Zhang J, Liang Z, Hu X, Cai H (1997) Controlled alternate partial rootzone irrigation: a new approach for water saving regulation in farmland. Agri Res Arid Areas 15: 1-6.

[2] English, M. and Raja, S. N., 1996. Perspectives on deficit irrigation. Agric. Water Manage. 32, pp. 1-14.

[3] Stoll M, Loveys B, Dry P (2000) Hormonal changes induced by partial rootzone drying of irrigated grapevine. Journal of Experimental Botany 51, 1627-1634. doi: $10.1093 /$ jexbot/51.350.1627.

[4] Kang S, Liang Z, Pan Y, Shi P, Zhang J (2000) Alternate furrow irrigation for maize production in an arid area. Agric Water Manag 45:267-274.

[5] Kang S, Zhang L, Hu X, Li Z, Jerie P (2001) An improve water use efficiency for hot pepper grown under controlled alternate drip irrigation on partial roots. Sci Hortic 89: 257-267.

[6] Kang S, Hu X, Goodwin I, Jerie P (2002) Soil water distribution, water use, and yield of response to partial root zone drying under a shallow groundwater table condition in a pear orchard. Sci Hortic 92:277-291.

[7] Kirda C, Cetin M, Dasgan Y, Topcu S, Kaman H, Ekici B, Derici MR, Ozguven AI (2004) Yield response of greenhouse grown tomato to partial root drying and conventional deficit irrigation. Agric Water Manage 69:191-202.

[8] Sadras VO (2009) Does partial root-zone drying improve irrigation water productivity in the Weld? A meta-analysis. Irri Sci 27:183-190.

[9] Morison JIL, Baker NR, Mullineaux PM, Davies WJ (2008) Improving water use in crop production. Philos Trans R Soc B Biol Sci 363:639-658.

[10] Kang S, Zhang J (2004) Controlled alternate partial root-zone irrigation: its physiological consequences and impact on water use efficiency. J Exp Bot 55:2437-2446.

[11] Shahnazari A, Liu F, Andersen MN, Jacobsen S-E, Jensen CR (2007) Effects of partial root-zone drying on yield, tuber size and water use efficiency in potato under Weld conditions. Field Crops Res 100:117-124.

[12] Zegbe JA, Behboudian MH, Clothier BE. 2004. Partial rootzone drying is a feasible option for irrigating processing tomatoes. Agricultural Water Management 68, 195-206.

[13] Zegbe JA, Behboudian MH, Clothier BE. 2006. Responses of 'Petopride' processing tomato to partial rootzone drying at different phenological stages. Irrigation Science 24, 203-210.

[14] Liu FL, Shahnazari A, Andersen MN, Jacobsen S-E, Jensen CR (2006) Physiological responses of potato (Solanum tuberosum L.) to partial root-zone drying: ABA signalling, leaf gas exchange, and water use efficiency. J Exp Bot 57: 3727-3735.

[15] Li F. Jiangmin Yu Mengling Nong, Shaozhong Kang, Jinhua Zhang.(2010) Partial root-zone irrigation enhanced soil enzyme activities and water use of Maize under different ratios of inorganic to organic nitrogen fertilizers Agricultural Water Management 97: 231-239.

[16] Kirda C, Topcu S, Cetin M, Dasgan HY, Kaman H, Topaloglu F, Derici MR, Ekici B (2007) Prospects of partial root zone irrigation for increasing irrigation water use efficiency of major crops in the Mediterranean region. Ann Appl Biol 150:281-291.

[17] Dodd IC, Theobald JC, Bacon MA, Davies WJ (2006) Alternation ofwet and dry sides during partial rootzone drying irrigation alters root-to-shoot signalling of abscisic acid. Functional Plant Biology 33, 1081-1089. doi: 10.1071/FP06203.

[18] Dodd I. C. (2007) Soil moisture heterogeneity during deficit irrigation alters root-to-shoot signalling of abscisic acid. Functional Plant Biology 34, 439-448.

[19] Hose E, Steudle E, Hartung W (2000) Abscisic acid and hydraulic conductivity of maize roots: a root cell- and pressure probe study. Planta 211, 874-882. doi: $10.1007 / \mathrm{s} 004250000412$.

[20] Sharp RE (2002) Interaction with ethylene: changing views on the role of abscisic acid in root and shoot growth responses to water stress. Plant, Cell and Environment 25, 211-222. doi: 10.1046/j.1365-3040.2002.00798.x.

[21] Hu Tiantian, Kang Shaozhong, Li Fusheng, Zhang Jianhua. 2011. Effects of partial root-zone irrigation on hydraulic conductivity in soil-root system for maize plant. Journal of Experimental Botany, 62 (12):4163-4172.

[22] Tyree, Melvin T. Patiño Sandra, Bennink John, Alexander John (1995) Dynamic measurements of root hydraulic conductance using a high-presure flow meter in the laboratory and field. Journal of Experimental Botany 282: 83-94.

[23] Böhm, W., 1979. Methods of Studying Root Systems Springer, Berlin.

[24] Darren M. Mingo, Julian C. Theobald, Mark A. Bacon, William J. Davies and Ian C. Dodd.(2004) Biomass allocation in tomato plants grown under partial rootzone drying: enhancement of root growth. Functional Plant Biology.31, 971-978.

[25] L. Wang H. de Kroon G. M. Bo gemann \& A. J. M. Smits Partial root drying effects on biomass production in Brassica napus and the significance of root responses Plant and Soil (2005) 276:313-326.

[26] Tanasescu, N., Paltineanu, C., 2004. Root distribution of apple tree under various irrigation systems within the hilly region of Romania. International Agrophysics 18, 175-180.

[27] J. Wang H. de Kroon L. Wang Root foraging and yield components underlying limited effects of Partial Root-zone Drying on oilseed rape, a crop with an indeterminate growth habit Plant and Soil (2009) 323: 163-176.

[28] Liang J, Zhang J, Wong MH. 1997. How do roots control xylem sap ABA concentrations in response to soil drying? Plant and Cell Physiology38, 10-16.

[29] J. Liang, J. Zhang and M. H. Wong Effects of air-filled soil porosity and aeration on the initiation and growth of secondary roots of maize (Zea mays) Plant and Soil (1996) 186: 245-254.

[30] Dodd, Ian C. Measuring and modeling xylem ABA concentration ([X-ABA]) in tomato plants exposed to deficit irrigation (DI) and partial rootzone drying (PRD). Acta Horticulturae (2008), 792: 225-231.

[31] Dodd, Ian C. Rhizosphere manipulations to maximize 'crop per drop' during deficit irrigation Journal of Experimental Botany 2009 60(9):2454-2459; doi:10.1093/jxb/erp192. 
[32] Fulai Liu, Ri Song, Xiaoyan Zhang, Ali Shahnazari, Mathias N. Andersen, Finn Plauborg, Sven-Erik Jacobsena and Christian R. Jensena Measurement and modelling of ABA signalling in potato (Solanum tuberosum L.) during partial root-zone drying. Environmental and Experimental Botany 2008 (63): 385-391.

[33] Yaosheng Wang, Fulai Liu, Mathias N. Andersen and Christian R. Jensen Improved plant nitrogen nutrition contributes to higher water use efficiency in tomatoes under alternate partial root-zone irrigation. Functional Plant Biology 2010 (37): 175182

[34] Darren M. Mingo Julian C. Theobald Mark A. Bacon, William J. Davies and Ian C. Dodd Biomass allocation in tomato (Lycopersicon esculentum) plants grown under partial rootzone drying: enhancement of root growth. Functional Plant Biology 2004(31):971-978.

[35] Kang S, Liang Z, Hu W, Zhang J (1998) Water use efficiency of controlled root-division alternate irrigation on maize plants. Agricultural Water Management 38, 69-76.

[36] Sharp RE, Hsiao TC, Silk WK (1990) Growth of the maize primary root at low water potentials. 2. Role of growth and deposition of hexose and potassium in osmotic adjustment. Plant Physiology 93, 1337-1346.

[37] Masia A, Pitacco A, Braggio L, Giulivo C (1994) Hormonal responses to partial drying of the root system of Helianthus annuus. Journal of Experimental Botany 45, 69-76.

[38] Zhang J, Davies WJ (1989) Abscisic acid produced in dehydrating roots may enable the plant to measure the water status of the soil. Plant, Cell and Environment 12, 73-81.
[39] North GB, Nobel PS (1991) Changes in hydraulic conductivity and anatomy caused by drying and rewetting roots of Agave deserti (Agavaceae). American Journal of Botany 78, 906-915.

[40] Martre P, North GB, Nobel PS (2001) Hydraulic conductance and mercury-sensitive water transport for roots of Opuntia acanthocarpa in relation to soil drying and rewetting. Plant Physiology 126, 352-362.

[41] Martre P, Morillon R, Barrieu F, North GB, Nobel PS, Chrispeels MJ (2002) Plasma membrane aquaporins play a significant role during recovery from water deficit. Plant Physiology 130, 2101-2110. James, A. Z. and William, R. G., 1998. Leaf water relations and plant development of three freeman maple cultivars subjected to drought. J. Am. Soc. Hort. Sci. 123, pp. 371-375.

[42] Gollan T, Passioura JB, Munns R.1986. Soil water status affects the stomatal conductance of fully turgid wheat and sunflower leaves. Australian Journal of Plant Physiology13, 459-464.

[43] Liu, C. X., Rubœk, G. H., Liu, F. L., Andersen, M. N., 2015. Effect of partial root zone drying and dificit irrigation on nitrogen and phosphorus uptake in potato. Agric. Water Manag. $159,66-76$.

[44] Wang Z, Liu F, Kang S, Jensen C R. 2012. Alternate partial rootzone drying irrigation improves nitrogen nutrition in maize (Zea mays L.) leaves. Environ Exp Bot. 75: 36-40.

[45] Karandish F, Shahnazari A. 2016. Soil temperature and maize nitrogen uptake improvement under partial root-zone drying irrigation. Pedosphere. 26 (6): 872-886. 